REYES-QUILODRÁN; Claudia; A LABRENZ, Catherine; DONOSO-MORALES, Gabriela. "Justicia Restaurativa en Sistemas de Justicia Penal Juvenil

Comparado: Suecia, Inglaterra, Italia y Chile".

Polít. crim. Vol. 13, No 25 (Julio 2018) Doc. 2, pp. 626 - 649.

[http://www.politicacriminal.cl/Vol_13/n_25/Vol13N25D2.pdf]

\title{
Justicia Restaurativa en Sistemas de Justicia Penal Juvenil Comparado: Suecia, Inglaterra, Italia y Chile
}

\section{Comparative Juvenile Criminal Justice Systems: Contrasts between Chile and Western Europe}

\author{
Claudia Reyes-Quilodrán \\ Master en Justicia Criminal, Ph. Doctor en Ciencia Política \\ Académico de la P. Universidad Católica de Chile \\ claudiar@uc.cl \\ Catherine A LaBrenz \\ Master en Trabajo Social, Ph. Doctor (C) en Trabajo Social
}

Steve Hicks School of Social Work, The University of Texas at AustinUniversity of Texas at Austinclabrenz@utexas.edu

Gabriela Donoso-Morales

Master en Trabajo Social

gedonoso@uc.cl

\section{Resumen}

La Justicia Restaurativa Juvenil ha sido implementada en los países de Europa Occidental por más de treinta años. Como es de esperar este proceso de implementación ha tenido etapas de aprendizaje en base a aciertos y desaciertos. Este estudio comparativo analiza la implementación de las prácticas de justicia restaurativa (JR) en los sistemas de justicia penal juvenil y la participación de los jóvenes infractores de ley en estos procesos en Suecia, Inglaterra, Italia y Chile. A través de entrevistas semi-estructuradas con profesionales de cada país, se indaga sobre las experiencias de las políticas y las prácticas de justicia restaurativa. Los hallazgos muestran la forma en que cada país implementa los programas de justicia restaurativa juvenil bajo escenarios jurídicos diferentes. Una de las principales barreras que debieron enfrentar durante su implementación fue que los distintos actores del sistema de justicia penal juvenil visualizaran el significado de la justicia restaurativa e intencionaran la participación de los jóvenes en estas prácticas. Estos resultados permiten conocer un marco de referencia para que un país como Chile, que se encuentra en una temprana etapa en el desarrollo de políticas y prácticas relacionadas con la justicia restaurativa, pueda incorporar este nuevo paradigma judicial.

Palabras claves: justicia restaurativa, jóvenes infractores de ley, sistemas de justicia penal juvenil, estudio comparado.

Palabras clave: justiciar reustarativa, criminalidad juvenil, sistema de justicia criminal juvenil, estudio comparativo. 
Polít. crim. Vol. 13, No 25 (Julio 2018) Doc. 2, pp. $626-649$.

[http://www.politicacriminal.cl/Vol_13/n_25/Vol13N25D2.pdf]

\begin{abstract}
Juvenile Restorative Justice has been implemented in Western European countries for more than thirty years; this aspect allows us to visualize and learn from them about the successes and failures that they had to face in the implementation of Juvenile Restorative Justice practices. This comparative study analyzes the implementation of Restorative Justice (RJ) in juvenile justice systems, and the participation of youth offenders in these processes in Sweden, England, Italy, and Chile. Semi-structured interviews were conducted with professionals in each country, to better understand their experiences with restorative policies and practices. The findings show how each country has implemented juvenile restorative justice within a different judicial framework. One of the main barriers that they had to face during their implementation was that the different actors of the juvenile justice system should visualize the meaning of restorative justice and intend to involve young people in these practices. These results provide us with a point of reference so that a country like Chile, which is in its early stages of development of policies and practices related to restorative justice, can build on the strengths of these other frameworks.
\end{abstract}

Key words: restorative justice, juvenile offenders, juvenile criminal justice system, comparative study.

\title{
1. Justicia Restaurativa Juvenil
}

Durante las últimas décadas, el concepto de justicia restaurativa (en adelante, JR) y prácticas restaurativas han sido introducidos en varios países. Aunque estas prácticas emergieron hace siglos atrás en comunidades indígenas como las esquimales y maoríes, ${ }^{1}$ sólo en los últimos 30 años han sido implementadas en el mundo occidental. Los movimientos sociales de los años 70 tuvieron una importante influencia en el sistema de justicia penal, pues cuestionaron las maneras más tradicionales y punitivas en el abordaje de los delitos y el tratamiento otorgado a los ofensores. ${ }^{2}$

En la justicia tradicional, argumenta Wright, ${ }^{3}$ la presencia del delito y los conflictos que éste conlleva son restados de las partes directamente involucradas, llegando el delito a desaparecer o convertirse en la propiedad de otros. Esta externalización del conflicto hacia el Estado o hacia un tercero minimiza la responsabilidad de los involucrados, evitando que

\footnotetext{
${ }^{1}$ WEITEKAMP, Elmar, "The History of Restorative Justice”, en BAZEMORE, Gordon and WALGRAVE, Lode, Restorative Juvenile Justice: Repairing the Harm of Youth Crime, New York: Criminal Justice Press. 1999, pp. 75-102.

BRAITHWAITE, John, "Restorative justice: Assessing optimistic and pessimistic accounts", Crime and Justice, no 25 (1999), pp. 1-127.

${ }^{2}$ WRIGHT, Martin, "Making good: Prisons, punishment and beyond", The Journal of Criminal Law and Criminology, no 74 (1983), pp. 1635-1638.

CHRISTIE, Nils, “Conflict as property”, British Journal of Criminology, nº 17(1977), pp. 1-15.

BRAITHWAITE, John, "Pride in criminological dissensus", Law \& Social Inquiry, Vol. 18, n³ (1993), pp. 501-512.

BRAITHWAITE, John, Restorative Justice and Responsive Regulation: The question of evidence. Regnet Research Paper No. 2014/51, Australian National University, 2014. file:///C:/Users/Usuario/Downloads/SSRN-id2514127.pdf [visitado el 07.12.2017].

CHRISTIE, Nils, “Conflict as property”, British Journal of Criminology, $n^{\circ}$ 17(1977), pp. 1-15.

${ }^{3}$ WRIGHT, "Making”, cit. nota n², pp. 1635.
} 
REYES-QUILODRÁN; Claudia; A LABRENZ, Catherine; DONOSO-MORALES,

Gabriela. "Justicia Restaurativa en Sistemas de Justicia Penal Juvenil

Comparado: Suecia, Inglaterra, Italia y Chile".

ellos comprendan las consecuencias de sus acciones. Se espera entonces que la incorporación de los procesos restaurativos pudiese permitir que los involucrados comprendan el daño provocado, con el fin de asumir la responsabilidad de sus actos y sus consecuencias.

En el año 2001, el Consejo de la Unión Europea ${ }^{4}$ (European Union Council, en adelante UEC) creó nuevas estrategias de prevención del delito, surgiendo la Justicia Restaurativa Juvenil (en adelante, JRJ) como una propuesta que integra diversas prácticas que se focalizan en la víctima, el ofensor y la comunidad. Más tarde, el UEC incorporó las recomendaciones de las Naciones Unidas ${ }^{5}$ para el ejercicio de la JR, promoviendo su implementación en la Comunidad Europea pues existe la convicción de que estas iniciativas podrían tener un impacto en la prevención de delitos y producir cambios en la cultura como la promoción de la paz. Este Consejo financia iniciativas restaurativas a través de la Red Europea de Puntos de Contacto Nacional para la Justicia Restaurativa (European Network of National Contact Points for Restorative Justice). ${ }^{6}$ No obstante esto último, ha existido un amplio debate sobre la efectividad de la JR. Por una parte investigaciones muestran resultados significativos respecto a la tendencia en la reducción de la reincidencia de los delitos y un alto nivel de satisfacción expresado tanto por las víctimas como por los agresores que han participado en procesos restaurativos. ${ }^{7}$ Asimismo, estudios de evaluación de impacto de largo plazo de programas JRJ mostraron que los jóvenes eran menos proclives a tener contacto con la policía, y tendían a involucrarse en delitos menos serios. ${ }^{8}$ A pesar de estos hallazgos, otras investigaciones no han encontrado evidencia significativa en la reducción de la reincidencia delictiva. ${ }^{9}$ Estos resultados han generado un debate

\footnotetext{
${ }^{4}$ EUROPEAN UNION COUNCIL, Framework Decision: The standing of victims in criminal proceedings, Article 10, 15 of March 2001, en: http://eur-lex.europa.eu/legalcontent/EN/TXT/?uri=CELEX\%3A32001F0220 [visitado el 07.12.2017].

${ }^{5}$ NACIONES UNIDAS, Manual sobre Programas de Justicia Restaurativa, United Nations Office on Drugs and Crime, New York, 2006, en: https://www.unodc.org/documents/justice-and-prisonreform/Manual_sobre_programas_de_justicia_restaurativa.pdf [visitado el 07.12.2017].

${ }^{6}$ EUROPEAN PARLIAMENT, European Network of National Contact Points for Restorative Justice, 2003, en: http://www.europarl.europa.eu/sides/getDoc.do?pubRef=-//EP//NONSGML+TA+P5-TA-20030147+0+DOC+PDF+V0//EN [visitado el 07.12.2017].

7 BONTA, James; WALLACE-CAPRETTA, Suzanne; ROONEY, Jennifer, Restorative Justice: An evaluation of the Restorative Resolutions Project, Ottawa: Solicitor General Canada, 1998.

BRAITHWAITE, John, Restorative Justice and Responsive Regulation, New York, Oxford University Press. 2002.

HAYES, Hennessey; DALY, Kathleen, "Conferencing and re-offending in Queensland", Australian and New Zealand Journal of Criminology, $\mathrm{n}^{\circ} 37$ (2004), pp.167-191.

LATIMER, Jeff; KLEINKNECHT, Steven, The Effects of Restorative Justice Programming: A review of the empirical, Ottawa: Department of Justice. Research and Statistics Division, 2000.

RODRIGUEZ, Nancy, "Restorative Justice, Communities, And Delinquency: Whom Do We Reintegrate?", Criminology and Public Policy, Vol. 4, nº 1 (2005), pp. 103-130.
}

${ }^{8}$ BERGSETH, Kathleen; COOPER, Maisha; BOUFFARD, Jeff, "Examining the effectiveness of a restorative justice program for various types of juvenile offenders", International Journal of Offender Therapy and Comparative Criminology, $\mathrm{n}^{\circ} 57(2012)$, pp.1054-1075.

9 MCCOLD, Paul; WACHTEL, Benjamin, Restorative Policing Experiment the Bethlehem Pennsylvania Police Family Group Conferencing Project, Community Service Foundation Pipersville, PA, 1998. 
Polít. crim. Vol. 13, No 25 (Julio 2018) Doc. 2, pp. $626-649$.

[http://www.politicacriminal.cl/Vol_13/n_25/Vol13N25D2.pdf]

constante sobre la implementación de prácticas restaurativas, por lo que resulta relevante poder conocer desde los mismos actores cómo se implementan estas prácticas en escenarios socioculturales diversos. En base a lo anterior, esta investigación tiene como objetivo el analizar cómo se implementan las prácticas de JRJ en Suecia, Inglaterra, Italia y Chile, y cómo las políticas públicas y el sistema de justicia penal juvenil de cada país facilitan este proceso, y qué barreras deben enfrentar para la implementación de la JRJ. Este estudio comparado tiene como fin el mostrar un marco referencial que oriente de mejor forma la puesta en marcha de procesos restaurativos en un país como Chile, que se encuentra en una etapa temprana de implementación.

\section{Metodología}

Se desarrolló un estudio de caso comparativo que incorpora cuatro países (tres de Europa Occidental y Chile). Para el levantamiento de información se hizo un corte en el tiempo en donde en un periodo determinado se realizó la recolección de datos. Se realizó un total de 33 entrevistas semi-estructuradas con profesionales que trabajan directamente en JRJ. Se indagó sobre sus experiencias en la implementación de las políticas públicas y las prácticas restaurativas. La selección de los países participantes en el estudio se intencionó basado en el tiempo y experiencia en la implementación de prácticas de JRJ. Suecia es el país con más antigüedad de los tres países europeos en su implementación, siguiendo Inglaterra y finalmente Italia. Cada uno de los países pertenecía a la Comunidad Económica Europea cuando se condujo la recolección de datos. Este hecho permitió conocer el cómo cada país implementa las directrices de la JRJ a pesar de contar con marcos jurídicos y sistemas de justicia penal juvenil diferentes.

El concepto de JR utilizado en este estudio adopta la definición otorgada por las Naciones Unidas al que denomina:

"Un proceso restaurativo es cualquier proceso en el que la víctima y el ofensor y, cuando sea adecuado, cualquier otro individuo o miembro de la comunidad afectado por un delito participan en conjunto de manera activa para la resolución de los asuntos derivados del delito, generalmente con la ayuda de un facilitador". ${ }^{10}$

En Suecia, se condujeron entrevistas semi-estructuradas a siete profesionales y dos expertos en JRJ. La mayoría de los profesionales en Suecia eran coordinadores de programas de mediación, y todos ellos eran facilitadores en las sesiones de mediación. Dos de los participantes en Suecia eran expertos en JR y habían llevado a cabo múltiples investigaciones en el tema, además de apoyar la implementación inicial de mediación en los años 80. Finalmente, se realizó un Focus Group con siete participantes, quienes eran mediadores en un programa de mediación de una municipalidad en el norte del país.

En Inglaterra, se entrevistó a ocho profesionales. Dos pertenecían al Local Partnership Advisor of the Youth Justice Board, dos eran académicos de universidades destacadas con experiencia e investigaciones en JR, y cuatro eran profesionales del Youth Offending

WOOD, William. "Why Restorative Justice Will Not Reduce Incarceration", The British Journal of Criminology $\mathrm{n}^{\circ} 55$ (2015), pp. 883-900. https://academic.oup.com/bjc/article/55/5/883/478399/WhyRestorative-Justice-Will-Not-Reduce.

${ }^{10}$ NACIONES UNIDAS, “Manual”, cit. nota n5, pp. 6. 
REYES-QUILODRÁN; Claudia; A LABRENZ, Catherine; DONOSO-MORALES,

Gabriela. "Justicia Restaurativa en Sistemas de Justicia Penal Juvenil

Comparado: Suecia, Inglaterra, Italia y Chile".

Service (en adelante, YOS). Se observaron sesiones de capacitaciones recibidas por los profesionales que trabajaban en el YOS.

En el caso de Italia, se entrevistaron a diez profesionales. Tres de ellos pertenecientes a programas diferentes de mediación. Tres eran trabajadores sociales de programas de libertad asistida, un educador de programa de libertad asistida, un juez de la Corte de Menores, un oficial del Ministerio de la Justicia, y un psicólogo de un centro semi-abierto. Adicionalmente, se observó una reunión mensual de cuatro programas de mediación en Roma, en donde se discutieron las experiencias de cada programa con casos específicos. Finalmente, en Chile, se realizaron entrevistas semi-estructuradas con seis profesionales. Los participantes nacionales eran trabajadores sociales y psicólogos y representaban tres programas distintos de reparación de daño en tres regiones del país.

Los participantes fueron reclutados mediante el uso de la técnica de informantes claves en cada uno de los lugares. Se identificaron expertos en justicia restaurativa en los cuatro países, llevando a cabo extensas búsquedas de literatura y estudios publicados por profesionales de cada país. Estos expertos fueron entrevistados para identificar a las personas clave involucradas en la implementación de prácticas de JR -incluyendo directores de centros de atención de Mediación entre Víctimas y Ofensores (en adelante VOM), profesionales del sistema de justicia penal juvenil y expertos en políticas relacionadas con la justicia juvenil. Además de la utilización de informantes clave, los investigadores también usaron la técnica del efecto de bola de nieve como un método para aumentar el número de participantes potenciales. Se realizaron menos entrevistas en Chile debido a la falta de implementación de programas de justicia restaurativa juvenil.

Se realizaron entrevistas semi-estructuradas con los profesionales identificados en cada lugar, utilizando una guía que se desarrolló en inglés y luego se tradujo al español para su uso en Italia y Chile. El instrumento consistió en 9 preguntas abiertas a los profesionales sobre el marco legal para la justicia restaurativa y su implementación de programas de Mediación entre Víctimas y Ofensores (VOM) y otras prácticas de JRJ.

En promedio las entrevistas tuvieron un rango de duración entre 47 minutos hasta 2 horas 15 minutos, con un promedio de 1 hora, 49 minutos. En todos los países estudiados se analizaron los distintos instrumentos legales y la evidencia empírica relevante en materia de JR. Se empleó análisis de contenido para el análisis de los datos, ${ }^{11}$ el cual fue realizado en dos etapas diferentes, de acuerdo con las pautas generales de Creswell ${ }^{12}$ y Paillé. ${ }^{13}$ Esto consistió en un análisis temático de aquellos conceptos comunes que emergieron de las entrevistas y de la triangulación de estos conceptos con documentos legales (legislación vigente y política federal y local). Este tipo de análisis se seleccionó debido a que permite la comparación y el contraste de los principales temas que surgieron en los cuatro países.

\footnotetext{
${ }^{11}$ PAILLE, Pierre, La méthodologie qualitative: Postures de recherche et travail de terrain. Paris, Francia: Armand Colin, 2006.

12 CRESWELL, John, Qualitative inquiry and research design: Choosing among five approaches (2 ${ }^{\text {nd }}$ edition), Thousand Oaks, CA: Sage Publications, 2007.

${ }^{13}$ PAILLE, "Chapter", cit. nota n ${ }^{\circ} 11$.
} 
Polít. crim. Vol. 13, No 25 (Julio 2018) Doc. 2, pp. $626-649$.

[http://www.politicacriminal.cl/Vol_13/n_25/Vol13N25D2.pdf]

En la siguiente sección se presenta el marco del sistema de justicia penal juvenil. Luego, las prácticas restaurativas de cada país son descritas. Es relévate precisar que la información presentada es la entregada por los distintos actores del sistema judicial que implementan las prácticas de justicia restaurativa. Posteriormente, los datos recolectados son analizados y comparados con la implementación de la JRJ en cada país.

\subsection{El Sistema Penal Juvenil en Suecia}

El Sistema Penal Juvenil en Suecia está conformado por Cortes Regionales, Cortes de Apelación y la Corte Suprema, sin división para jóvenes infractores de ley. En el evento de casos penales, se asigna un fiscal y un abogado defensor, este último en el caso de que el imputado no puede financiar uno privado. La edad de imputabilidad para los adolescentes empieza a los 15 años, donde los menores de 15 años que han cometido un delito grave, son derivados a los servicios sociales para evaluación psicosocial. Los adolescentes de 15 años y más son procesados dentro del mismo sistema que los adultos, aunque las sanciones son reducidas para los jóvenes infractores entre los 15 y 20 años de edad, llegando a ser escaso los casos de sentenciados a cumplir condenas en prisión o libertad asistida, especialmente aquellos adolescentes entre 15 a 17 años, cuyos delitos tienden a ser hurtos y uso de drogas. ${ }^{14}$ La tendencia es aplicar condenas más punitivas sólo después de considerar cualquier otra sanción alternativa. ${ }^{15}$

Una vez condenado un joven infractor de ley, existen tres tipos de sentencia: un plan especializado de necesidades, servicio comunitario, y/o condenas de encarcelación. Los centros cerrados para jóvenes infractores de ley en Suecia son administrados directamente por el Ministerio de Justicia. En el caso de los servicio comunitario y/o el plan especializado de necesidades, son implementados por los servicios municipales $\mathrm{y} / \mathrm{u}$ organizaciones privadas con o sin fines de lucro. ${ }^{16}$

\subsubsection{La Justicia Restaurativa en Suecia}

En los años 80, el gobierno federal de Suecia traspasó la responsabilidad de administración de proyectos y estudios sobre mediación al Consejo Nacional de Prevención del Delito (National Crime Prevention Council, en adelante BRA). En este tiempo, las prácticas restaurativas ya habían emergido en otros países, por lo que posteriormente y en respuesta a las políticas y la influencia de los países bajos, el BRÅ asumió la supervisión de los proyectos de mediación a partir de 1998 e implementó proyectos de JR en distintas municipalidades. En el año 2000, BRÅ emite un informe al parlamento, el cual reporta los hallazgos de estos proyectos. ${ }^{17}$ En respuesta a los resultados arrojados por este informe se introdujo el Acta de Mediación a los estatutos suecos en el 2002, que entrega una guía de mediación para los participantes.

Sin embargo, en 2008, el parlamento agregó una cláusula al Acta de 2002, desplazando la

\footnotetext{
${ }^{14}$ AXELSSON, Erik, Young offenders and juvenile justice in Sweden, Riksdag Research Service Stockholm, Sweden SN/SG/5278, 2008.

${ }^{15}$ SWEDISH PENAL CODE, Chapter 29, Section 7, Stockholm, Sweden, 1962, en: http://www.parliament.am/library/Qreakan/shwedia.pdf [visitado el 07.12.2017].

${ }^{16}$ SWEDISH PENAL CODE, "Chapter", cit. nota ${ }^{\circ} 15$.

17 JACOBSSON, Maritha; WAHLIN, Lottie; ANDERSSON, Tommy, "Victim offender mediation in Sweden: Is the victim better off?" International Review of Victimology, Vol. 18 n³(2012), pp. 229-249.
} 
REYES-QUILODRÁN; Claudia; A LABRENZ, Catherine; DONOSO-MORALES,

Gabriela. "Justicia Restaurativa en Sistemas de Justicia Penal Juvenil

Comparado: Suecia, Inglaterra, Italia y Chile".

responsabilidad del BRÅ a las municipalidades, dejándolas a cargo de ofrecer mediación a los adolescentes infractores de ley entre 12 y 21 años. ${ }^{18}$ Esta descentralización ha generado que algunas municipalidades pequeñas (menos de 50.000 habitantes) y que no cuentan con recursos suficientes trasladen los casos a municipalidades más grandes, con el fin de aunar y potenciar los recursos entre los municipios, pues cada municipalidad tiene como obligación ofrecer algún tipo de mediación a todos los adolescentes infractores de ley que hayan admitido su culpabilidad y su deseo de participar. En la actualidad de un total de 290 municipalidades suecas, 154 ofrecen programas de mediación. ${ }^{19}$

Cuando se imputa a algún joven entre los 15 y 20 años de edad de algún delito, es detenido y llevado a la estación de policía, si el joven admite total o parcialmente su culpabilidad, la policía está mandatada a preguntarle por su interés en participar en una sesión de mediación con la víctima. Si el joven acepta, la policía envía la información de contacto al coordinador del programa de mediación en la municipalidad correspondiente, y se realiza una primera reunión para indagar sobre las motivaciones del joven en participar y si sería un buen candidato para la mediación. Ambas partes tienen que estar de acuerdo con el proceso para realizar una sesión de mediación víctima-ofensor. Por lo general, este proceso se conduce en paralelo al proceso judicial, y no reemplaza la sentencia de la corte.

\subsection{El Sistema Penal Juvenil en Inglaterra}

El Acta del Crimen y Desorden de $1998^{20}$ (Crime and Disorder Act) establece que la edad de imputabilidad en adolescentes es entre los 10 y 17 años en Inglaterra. Según el tipo y la gravedad del delito se deriva a una corte: La Corte Juvenil aborda delitos menores como por ejemplo robo, hurto e infracciones por drogas. En el caso de delitos más graves, como homicidio, violación sexual o delitos que implicaría una condena superior a 14 años para los adultos, el proceso judicial que se inició en la Corte Juvenil es derivado a la Corte de la Corona (Crown Court). En este contexto, hay dos tipos de sentencias que dependen de la gravedad y las circunstancias del crimen. La primera sentencia refiere a las órdenes de detención y capacitación que se aplican a los niño/as y adolescentes entre 10 a 17 años, que podría consistir en una simple detención o servicios a la comunidad. La segunda sentencia se trata de sentencias comunitarias, tales como órdenes de derivación a programas de reparación del daño causado y rehabilitación. Dentro de las órdenes de rehabilitación se encuentra la JRJ, que requiere de la participación voluntaria del ofensor y la víctima. Un actor relevante en este proceso es el Directorio de la Justicia Juvenil (Youth Justice Board, en adelante YJB), organismo público, patrocinado por el Ministerio de la Justicia, establecido por el Acta del Crimen y la Desorden. ${ }^{21}$

\subsubsection{La Justicia Restaurativa en Inglaterra}

${ }^{18}$ LEY N $\mathrm{N}^{\mathrm{o}}$ 2002:445, Mediation Act 445, Lag om medling med anledning av brott [Mediation Act], Swedish Code of Statutes, Stockholm, 2002, en: https://www.riksdagen.se/sv/dokument-lagar/dokument/svenskforfattningssamling/lag-2002445-om-medling-med-anledning-av-brott_sfs-2002-445 [visitado el 07.12.2017].

${ }_{19}$ WAHLIN, Lottie. Victim offender mediation in the $21^{\text {st }}$ Century, National Council for Crime Prevention, Stockholm, Sweden, 2005.

${ }^{20}$ ACTA DEL CRIMEN Y DESORDEN - Crime and Disorder Act, Established the Youth Justice System of England and Wale's legal support, 1988, en: http://www.legislation.gov.uk/ukpga/1998/37 [visitado el 07.12.2017].

${ }^{21}$ ACTA DEL CRIMEN Y DESORDEN “Established”, cit. nota n²0. 
Polít. crim. Vol. 13, No 25 (Julio 2018) Doc. 2, pp. $626-649$.

[http://www.politicacriminal.cl/Vol_13/n_25/Vol13N25D2.pdf]

El YJB ha implementado programas de justicia restaurativa desde el 2001, y destaca a la JRJ como el modelo de intervención más importante del sistema penal juvenil, ya que reduce la reincidencia, apoya a las víctimas y construye confianza pública. ${ }^{22}$ En este contexto, todos los entrevistados señalaron que el éxito de este modelo radica en la participación voluntaria de la víctima y el ofensor; y que cada infractor y víctima debería tener la oportunidad de participar, independiente de la gravedad de delito, puesto que el principal beneficiado del proceso es la víctima, sintiéndose gratificado/a y más segura/o luego de haber participado de la mediación, mientras que los jóvenes infractores tienen la oportunidad de visualizar el daño causado en otras personas previniendo la reincidencia.

En la actualidad, Inglaterra implementa distintos tipos de programas de JRJ, tales como Mediación entre la Víctima y el Ofensor (VOM), conferencias restaurativas y conferencias familiares. A continuación se describe cada una de ellas:

\section{a) La mediación entre víctima-ofensor (VOM)}

Este modelo de mediación busca facilitar el diálogo entre la víctima y ofensor, a través de un mediador capacitado en mediación y en los principios de la JRJ. El mediador tiene una entrevista preliminar con la víctima y el joven infractor individualmente, donde se explican los objetivos de la mediación y las distintas etapas que este proceso implica. Posteriormente, el mediador acompaña a ambos a la sesión de mediación. En algunos programas, contaban con un mediador para el infractor y otro para la víctima, mientras que en otros programas tenían un único profesional que intervenía con ambos. En la sesión de mediación los participantes (ofensor y víctima) pueden llegar a adoptar acuerdos de medidas reparatorias. En esta etapa el mediador cumple un papel importante, pues visualiza que estas medidas reparatorios sean factibles de implementar y no repliquen daño a ninguna de las partes involucradas. Estos acuerdos posteriormente son monitoreados por el programa para verificar su cumplimiento.

\section{b) Conferencias restaurativas}

Se diferencia esta práctica de VOM por la presencia de otros miembros de la familia o de personas significativas de la víctima y/o infractor. En la Conferencia Restaurativa, el profesional entrevista a cada participante por separado. Esta práctica recibe este nombre pues una vez entrevistado cada uno de los participantes (víctima-ofensor y sus familiares o significativos) se les convoca a una sesión de mediación en donde cada uno de ellos expresa cómo ha vivenciado el delito perpetrado y las consecuencias personales que le han significado para él/ella y su familia. En la conferencia se llegan a acuerdos reparatorios, que posteriormente son monitoreados por el medidor para evaluar su cumplimiento.

c) Conferencias familiares grupales

22 YOUTH JUSTICE BOARD. Developing restorative justice: An action plan, London, 2006, en: http://restorativejustice.org/rj-library/developing-restorative-justice-an-action-

plan/7508/\#sthash.Fv0IBqEq.dpbs [visitado el 07.12.2017]. 


\section{REYES-QUILODRÁN; Claudia; A LABRENZ, Catherine; DONOSO-MORALES, Gabriela. "Justicia Restaurativa en Sistemas de Justicia Penal Juvenil Comparado: Suecia, Inglaterra, Italia y Chile".}

Consisten en la participación de los miembros de la familia extensa, en donde participan en el proceso y co-construyen la solución. Los profesionales indicaron que las familias que participaban solían pertenecer a clases socioeconómicas más vulnerables y algunos grupos de migrantes, por lo que el proceso de reparación se puede ver dificultado dado a las diferencias del idioma y de la cultura de los miembros participantes. Estos elementos influyen en que las Conferencias Familiares Grupales no sean una práctica frecuente. A pesar de estas limitaciones, los profesionales señalaron que la comunidad es una parte esencial de la JRJ, ya que pueden comprender la idea central del proceso como una reparación del daño producido por el delito, la cual requiere de la participación activa del ofensor, la víctima y la comunidad.

\subsection{El Sistema Penal Juvenil de Italia}

En Italia, la edad de imputabilidad juvenil es entre 14 y 17 años. Las Cortes de Menores abordan los casos tanto de adolescentes infractores de ley como de niños y adolescentes vulnerados en sus derechos. El objetivo del sistema penal juvenil en Italia es minimizar el contacto de los jóvenes infractores con el sistema penal, pues consideran este contacto como un factor de riesgo, ya que reconocen que la detención interrumpe el proceso de maduración y de educación del adolescente.

En el año 1988, se aprobó el Decreto $\mathrm{N}^{\circ}$ 488/1988 del Presidente de la República que regula el procedimiento penal para los menores de edad, el cual requirió que la Corte de Menores evaluara alternativas antes de ingresar a algún adolescente a un centro de detención. ${ }^{23} \mathrm{El}$ decreto estableció tres alternativas: los jueces pueden declarar que un delito no es relevante y lo pueden desestimar; pueden decretar un perdón si creen que el joven infractor no volverá a cometer este delito o algún otro; o pueden ordenar messa alla prova ("libertad asistida" antes del juicio). Los jueces pueden decretar messa alla prova independiente del delito cometido por el adolescente, llegando a ser una alternativa viable hasta en casos de homicidio. ${ }^{24}$ La messa alla prova se puede implementar por cuatro o cinco años, antes de que el tribunal emita una sentencia, y tiene como objetivo desarrollar un programa de intervención individual con el adolescente, buscando mejorar las condiciones psicosociales del joven, reducir los factores de riesgo y promover los factores protectores, con el fin de prevenir la reincidencia delictual y generar las condiciones necesarias para favorecer su desarrollo integral.

En estos casos, el fiscal tiene un papel importante en exponer los problemas psicosociales que afectan al joven, para así poder sugerir al juez la mejor sanción, que tiene como objetivo principal promover el bienestar del niño/a. La sugerencia del fiscal es apoyada por las recomendaciones del trabajador social, quien realiza la evaluación social del niño/a y su grupo familiar, y en base a los antecedentes psicosociales puede sugerir messa alla prova,

\footnotetext{
${ }^{23}$ DECRETO $\mathrm{N}^{\circ}$ 448/1988, Approvazione delle disposizioni sul processo penale a carico di imputati minorenni. Decreto del Presidente della Repubblica, 1988, 448/88. http://www.altrodiritto.unifi.it/ricerche/minori/rugi/cap2.htm [visitado el 07.12.2017].

${ }^{24}$ NELKEN, David. "Italian juvenile justice: Tolerance, leniency or indulgence?", Youth Justice, Vol. 6, n² (2006), pp. 107-128.
} 
Polít. crim. Vol. 13, No 25 (Julio 2018) Doc. 2, pp. $626-649$.

[http://www.politicacriminal.cl/Vol_13/n_25/Vol13N25D2.pdf]

por lo que el juez puede tomar una decisión basada en la evaluación psicosocial del joven y su grupo familiar. En este escenario el abogado defensor está prácticamente ausente, ya que el juez, el fiscal y los servicios sociales están a cargo de conocer los motivos que determinan el por qué el adolescente comete la infracción de ley.

\subsubsection{La Justicia Restaurativa Juvenil en Italia}

En Italia, los primeros proyectos restaurativos se implementaron en el año 2000. El Decreto del Presidente de la República No488/1988, ${ }^{25}$ el Decreto Legislativo No 272/1989 ${ }^{26}$ y la Ley $\mathrm{N}^{\mathrm{o}} 285^{27}$ le otorgó un marco legal en el que se considera las prácticas de JRJ como una herramienta para educar a los adolescentes infractores. Aunque Italia no cuenta con ningún instrumento legal específico para la ejecución de la JRJ, como es el caso de los otros países, la ley italiana permite que se implementen estos programas de mediación, puesto que la ley vela por el desarrollo integral del adolescente. Entre el año 1996 hasta el 2006, Italia presentó una fuerte tendencia a disminuir la cantidad de jóvenes infractores detenidos y condenados. ${ }^{28}$ Los entrevistados explican esta tendencia al hecho de que durante ese periodo Italia comenzó a implementar prácticas innovadoras, que dio origen a las prácticas actuales. No obstante, no se cuenta con evidencia empírica que ratifique esta impresión.

\section{a) Programas de Mediación en Italia}

El ingreso al sistema de justicia juvenil ocurre cada vez que algún policía detiene a un adolescente menor de 18 años. Cuando la policía detiene al joven, su obligación es informar al fiscal encargado de los casos de menores de edad, y a los servicios sociales, para que evalúe la evidencia y determine si se pondrá a disposición de la Corte de Menores. Los servicios sociales inician las evaluaciones psicosociales e informan al juez y al fiscal para determinar si aplica la messa alla prova u otra sanción. En esta instancia los jóvenes tienen la oportunidad de asistir a algún programa de mediación de forma voluntaria, a través de la orden del juez o del fiscal.

El Decreto Legislativo 267/2000 29 dio espacio a la creación de un protocolo en donde las organizaciones se comprometieron a implementar prácticas restaurativas con el apoyo de los centros de mediación. En este periodo se implementan cinco centros en cinco regiones distintas, los que recibieron apoyo económico de diversas fuentes de derecho privado. Los programas públicos recibieron el financiamiento del Centro de Justicia de Menores, la Corte de Menores, la Fiscalía, y las municipalidades. Los programas privados, como el

\footnotetext{
${ }^{25}$ DECRETO No 448/1988 “Approvazione", cit. nota n²3.

${ }^{26}$ DECRETO LEGISLATIVO No 272/1989, Approvazione delle disposizioni sul processo penale a carico di imputati minorenni, DL 272/89, 1989, en: http://www.regione.abruzzo.it/procuraminori/docs/legislazione/Norme_attuative_DLgs_28071989.pdf [visitado el 07.12.2017].

${ }^{27}$ LEY N 285 Disposizioni per la promozione di diritti e di opportunità per l'infanzia e l'adolescenza. Gazzetta Ufficiale, 1997, http://www.camera.it/parlam/leggi/972851.htm [visitado el 07.12.2017].

${ }^{28}$ HARRENDORF, Stefan; HEISKANEN, Markku; MALVY, Steven. International statistics on crime and justice, European Institute for Crime Prevention and Control Affiliated with United Nations, 2010.

29 DECRETO LEGISLATIVO No 274/2000, "Disposizioni sulla competenza penale del giudice di pace, a norma dell'articolo 14 della legge 24 novembre 1999, n. 468", 2000, en http://www.camera.it/parlam/leggi/deleghe/00274dl.htm [visitado el 07.12.2017].
} 
REYES-QUILODRÁN; Claudia; A LABRENZ, Catherine; DONOSO-MORALES,

Gabriela. "Justicia Restaurativa en Sistemas de Justicia Penal Juvenil

Comparado: Suecia, Inglaterra, Italia y Chile".

Centro de Mediación de Palermo, recibió el apoyo económico del Instituto Don Loncalabrio y de la Universidad de Palermo. Cada uno de los programas se apega a las guías de las Naciones Unidas para la Justicia Restaurativa. ${ }^{30}$ Cuentan con un promedio de 6 profesionales por equipo, además de un grupo de voluntarios que han recibido capacitaciones en mediación. Uno de los centros con mayor dotación es el Centro de Mediación de Palermo que cuenta con cinco psicólogos, dos abogados, un sociólogo, dos trabajadores sociales y dos educadoras. El equipo trabaja con mediación escolar, para prevenir el delito y escalamiento de conflictos mediante la participación de la comunidad escolar. También provee capacitaciones en mediación para sensibilizar a la comunidad, atendiendo en el periodo de un año, aproximadamente a 80 jóvenes.

Estos centros realizan mediación entre los ofensores y las víctimas (VOM), que como en el caso de Inglaterra involucran al adolescente que ha admitido completa o parcialmente su responsabilidad en el delito que se le imputa, la víctima y un mediador. El mediador conduce la primera entrevista con el infractor para evaluar la posibilidad de seguir con el proceso. En la siguiente fase, se conduce una segunda entrevista con la víctima, en donde se informa sobre el proceso de mediación, y se confirma si la víctima aún tiene interés en continuar. Posteriormente, se fija la sesión de mediación, en donde dos mediadores, la víctima y el adolescente infractor participan, y tanto el ofensor como la víctima pueden ser acompañados por sus padres o algún adulto responsable. Esto es denominado mediación directa, pues cada una de las partes expresa en la sesión cara a cara como vivenció el delito, y el ofensor tiene la oportunidad de pedir disculpas por sus acciones, construyéndose un acuerdo que ambos firman. Asimismo, la víctima también tiene la oportunidad de expresar qué implicancias tuvo para ella/el la perpetración del delito, y puede proponer una acción concreta para reparar el daño causado. El mediador realiza un seguimiento que evalúa si se cumplieron los acuerdos e informa al juez o al fiscal.

La mediación indirecta ocurre cuando la víctima no desea reunirse con el ofensor, de modo que le escribe una carta en donde expresa cómo se siente y cómo el delito le ha afectado. El joven infractor puede responder a la carta bajo la supervisión del mediador. En algunos de estos casos, los adolescentes infractores asisten a los servicios comunitarios simultáneamente, de tal forma que es la oficina que está a cargo de los servicios en beneficio a la comunidad, a través de un trabajador social, quien realiza el seguimiento para monitorear que el adolescente infractor asista y concluya los compromisos adoptados en la sesión de mediación.

En la cultura italiana, la familia extensa juega un rol importante en la crianza de los niños y en la toma de decisiones familiares. Además, las personas participan activamente en las actividades comunitarias, conservando el capital social. ${ }^{31}$ Esto hace que la presencia de la comunidad en las prácticas restaurativas no sólo ayuda a prevenir el delito, sino que también permite que la comunidad se haga parte de las soluciones. Esto se debe a que los miembros de la comunidad son capaces de visualizar las causas que están a la base de la

\footnotetext{
${ }^{30}$ NACIONES UNIDAS, “Manual”, cit. nota n5, pp. 6.

31 PUTMAN, Robert, Bowling alone: The collapse and revival of American community, New York, NY: SAGE, 2000.
} 
Polít. crim. Vol. 13, No 25 (Julio 2018) Doc. 2, pp. $626-649$.

[http://www.politicacriminal.cl/Vol_13/n_25/Vol13N25D2.pdf]

conducta violenta o desadaptativa de los niños y adolescentes. La presencia de la comunidad en la prevención del delito crea un círculo virtuoso, ya que su participación genera capital social, y con ello redes de apoyo tanto para las víctimas como para los ofensores, condiciones que ayudan a promover conductas prosociales. ${ }^{32}$

\section{b) Programas de Sanciones del Sistema Penal Juvenil en Italia}

Durante la messa alla prova y durante la ejecución de la sanción, ya sea en los programas de libertad asistida o internación en centros cerrados o semi-abiertos, el plan de intervención individual para los jóvenes es implementado. Estos programas cuentan con componentes de JR. El Decreto $\mathrm{N}^{\circ} 488 / 1988^{33}$ señala que el adolescente aún no ha llegado a una madurez completa, y por lo tanto requiere de una intervención educativa para prevenir que cometa infracciones en el futuro. Bajo esta premisa, se integra las prácticas de justicia restaurativa como una herramienta educativa, en donde el joven debe asumir la responsabilidad de sus acciones, y reparar el daño causado. Los profesionales señalaron que esta práctica efectivamente ayuda al adolescente a percibir sus propias acciones y visualizar las consecuencias y alcances del daño provocado. Las prácticas restaurativas son una parte de los objetivos del plan de intervención individual del adolescente, pues el programa también implementa otros objetivos que buscan el mejoramiento de las condiciones psicosociales del adolescente.

En cuanto a las familias que participan, los profesionales identifican dos grupos: El primer grupo corresponden a familias de escasos recursos económicos, que viven en barrios vulnerables y presentan problemas familiares como el consumo problemático de drogas, violencia intrafamiliar, desempleo e involucramiento en delitos previos. El segundo grupo consiste en familias que pertenecen a la clase media italiana y también al segmento social con recursos económicos escasos, pero no presentan los mismos problemas sociales, y en estos casos suele ser el primer delito cometido por el adolescente, que generalmente corresponden a delitos menores, como lesiones, amenazas y agresiones verbales.

\subsection{Sistema Penal Juvenil en Chile}

En Chile la Ley $20.084^{34}$ de Responsabilidad Penal Adolescente (en adelante, LRPA) entró en vigencia el año 2007 en respuesta a la ratificación del país de la Convención de los Derechos del Niño en 1990, ${ }^{35}$ que obliga a adoptar medidas en favor de la infancia, en las

\footnotetext{
${ }^{32}$ DABAS, Elina; NAJMANOVICH, Denise, Redes: El lenguaje de los vínculos hacia la construcción el fortalecimiento de la sociedad civil, Buenos Aires, Argentina: Paidós, 1999.

ANSARI, Sami, "Social Capital and Collective Efficacy: Resource and Operating Tools of Community Social Control", Journal of Theoretical and Philosophical Criminology Social Capital \& Collective Efficacy, Vol. 5 No2 (2013), pp. 75- 94.

${ }^{33}$ DECRETO No 448/1988 “Approvazione", cit. nota n²3.

${ }^{34}$ LEY No 20.084, Establece un Sistema de Responsabilidad de los Adolescentes por Infracciones a la Ley Penal. Ministerio de Justicia, Chile, 2007, en https://www.leychile.cl/Navegar?idNorma=244803[visitado el 07.12.2017].

35 CONVENCIÓN SOBRE LOS DERECHOS DEL NIÑO, Naciones Unidas, 1989, en: http://www.unicef.cl/web/informes/derechos nino/convencion.pdf [visitado el 07.12.2017].
} 
REYES-QUILODRÁN; Claudia; A LABRENZ, Catherine; DONOSO-MORALES,

Gabriela. "Justicia Restaurativa en Sistemas de Justicia Penal Juvenil

Comparado: Suecia, Inglaterra, Italia y Chile".

que también considera a los adolescentes infractores de ley. ${ }^{36}$ La LRPA considera como imputables a adolescentes entre 14 y 17 años de edad, enfocándose en un marco socioeducativo que promueve la inserción social y la rehabilitación de dichos adolescentes. Esta ley establece que si bien los Tribunales de Garantía están a cargo de los procesos de delitos juveniles y de adultos, cada tribunal debe contar con una sala especializada que atiende los casos de los adolescentes, y en el proceso penal el adolescente tiene derecho a un abogado defensor especializado en el tramo etario, mientras que el fiscal de la causa legal también debe contar con dicha especialización. Las sanciones penales dependen en gran parte de la gravedad del delito e involucramiento previo con el sistema penal, independiente de las necesidades psicosociales del adolescente, criterios que son similares al sistema penal de adultos que es persecutorio y punitivo. ${ }^{37}$

Según la LRPA, el fiscal debe recoger evidencia sobre el delito, mientras que el abogado defensor intenta reducir la sanción, sin que los problemas psicosociales del adolescente puedan llegar a ser relevantes en el proceso judicial. ${ }^{38}$ En casos muy excepcionales, el juez solicita evaluación a un equipo especializado, sin que esta sea una práctica común de los Juzgados de Garantía. En la actualidad, en Chile se debate sobre la pérdida de especialización en temas de adolescencia en los jueces, fiscales y abogados defensores. Esta pérdida se atribuye a la alta demanda de casos que cada uno de estos actores judiciales debe atender, dejándose a un lado la experticia de cada uno de ellos ante esta demanda; como también a la ausencia de especialización en materia infantojuvenil ${ }^{39}$.

Una vez dictada la sentencia, es el Estado a través del Servicio Nacional de Menores (en adelante SENAME) que está a cargo de implementar la sanción. SENAME tiene la administración directa de los centros juveniles de privación de libertad y los centros semicerrados. Las sanciones ambulatorias tales como: libertad asistida, servicios en beneficio a la comunidad, salida alternativa y reparación del daño, son administrados por organizaciones privadas sin fines de lucro que son supervisadas y financiadas por SENAME según la Ley $\mathrm{N}^{\circ} 20.032 .{ }^{40}$ La sanción máxima que un adolescente puede recibir es de 10 años en un centro de reclusión juvenil.

${ }^{36}$ OYARZÚN Astrid, DÁVILA Oscar, GHIARDO, Felipe, HATIBOVIC, Fuad ¿Enfoque de derechos o enfoque de necesidades? Centro de Estudios Sociales, SENAME. 2008, en: http://es.scribd.com/doc/92434342/Enfoque-de-Derecho-o-Enfoque-de-Necesidades. [visitado el 07.12.2017].

${ }^{37}$ AGUIRREZABAL, Maite; LAGOS, Gladys; VARGAS, Tatiana, "Responsabilidad penal juvenil: hacia una "justicia individualizada", Revista de Derecho, Vol. XXII, $\mathrm{n}^{\circ}$ 2, (2009), pp. 137-159, en: http://www.redalyc.org/pdf/1737/173714177008.pdf [visitado el 07.12.2017].

${ }^{38}$ AGUIRREZABAL, "Responsabilidad", cit. Nota n 37, p. 143.

${ }^{39}$ MELO, Ronaldo, Guardar silencio: El desafío de la especialización en el sistema de justicia penal adolescente, Revista 93: La revista de la Defensoría Nacional Pública, Vol.9 (2013), pp. 55-57. http://www.dpp.cl/resources/descargas/revista93/revista93n9.pdf [visitado el 07.12.2017].

PADILLA, Marcelo, Examen y Contraexamen: Iván Fuenzalida y Sebastián Valenzuela, Revista 93: La revista de la Defensoría Nacional Pública, Vol. 9 (2013). pp. 14-2. http://www.dpp.cl/resources/descargas/revista93/revista93n9.pdf [visitado el 07.12.2017].

${ }_{40}$ LEY N $\mathrm{N}^{\circ}$ 20.032, Establece Sistema de Atención a la Niñez y Adolescencia A través de la Red de Colaboradores del SENAME, y su Régimen de Subvención, Ministerio de Justicia, Chile, 2015, en: http://www.sename.cl/wsename/otros/proteccion/ley20032.pdf [visitado el 07.12.2017]. 
Polít. crim. Vol. 13, No 25 (Julio 2018) Doc. 2, pp. 626 - 649.

[http://www.politicacriminal.cl/Vol_13/n_25/Vol13N25D2.pdf]

\subsubsection{Programas Justicia Restaurativa Juvenil en Chile}

En Chile, se implementa una forma reconocida como JRJ que es la reparación del daño. Sólo una corporación está a cargo de implementar los programas de reparación de daño y cuenta con cuatro programas en distintas regiones del país, donde cada uno cuenta con una dupla psicosocial conformada por un trabajador social y un psicólogo a cargo del proceso.

Los entrevistados indicaron que recibían en promedio cinco casos al año. Este hecho lo explican debido a que los fiscales, abogados defensores y jueces tienden a no proponer y/o aplicar con frecuencia esta sanción, pese a tener reuniones frecuentes con los jueces para explicarles los beneficios de esta práctica restaurativa. Los profesionales han participado en capacitaciones breves de prácticas de JRJ, y han implementado mediación directa a través de VOM. Una de las dificultades que el programa de reparación del daño ha debido enfrentar es la distribución geográfica de los casos. Esto es, los profesionales deben cubrir una región del país que cuenta en promedio con una superficie terrestre por sobre los 16.000 kilómetros cuadrados. Esto implica que la dupla profesional viaje largas distancias para poder comunicarse cara-a-cara con los jóvenes.

Adicionalmente, los mismos profesionales atienden casos en el programa de servicios en beneficio a la comunidad. Cada profesional tiene en promedio 20 casos, y para cada caso deben formular un plan de intervención. El programa de servicios en beneficio de la comunidad requiere que los adolescentes dediquen una cantidad de horas semanales al desarrollo de actividades. Como primera acción, el trabajador social evalúa los intereses del adolescente, y coordina con alguna institución pública o privada para que el joven participe realizando las actividades acordadas con la institución y el adolescente. El perfil de los adolescentes que participan en ambos programas es amplio: algunos tienen alto compromiso delictual, mientras otros tienen bajo compromiso delictual y muy poco contacto con el sistema de justicia penal. La participación de la familia es escasa, ya que la sanción se enfoca principalmente en el adolescente infractor.

En Chile aún no existen centros que aborden específicamente la mediación entre los jóvenes infractores y las víctimas, y las prácticas restaurativas son aisladas. Una razón que podría explicar este aspecto es el hecho que el sistema penal Chileno es de carácter punitivo, en donde los actores judiciales son los llamados a determinar la sentencia, y la víctima tendería a ser invisibilizada. ${ }^{41}$ Asimismo, los entrevistados indican que en los programas juveniles de reparación del daño no se realiza, en forma sistemática, seguimiento de casos y no existen evaluaciones de impacto en esta materia. De tal forma que la escasa información existente no permite identificar cuáles son las mejores medidas y prácticas aplicadas a los adolescentes, y en qué aspectos el plan de intervención puede impactar en la reducción de la conducta desadaptativa y delictiva. Muy por el contrario, la reparación del daño y los servicios en beneficio de la comunidad son consideradas sanción de acuerdo al

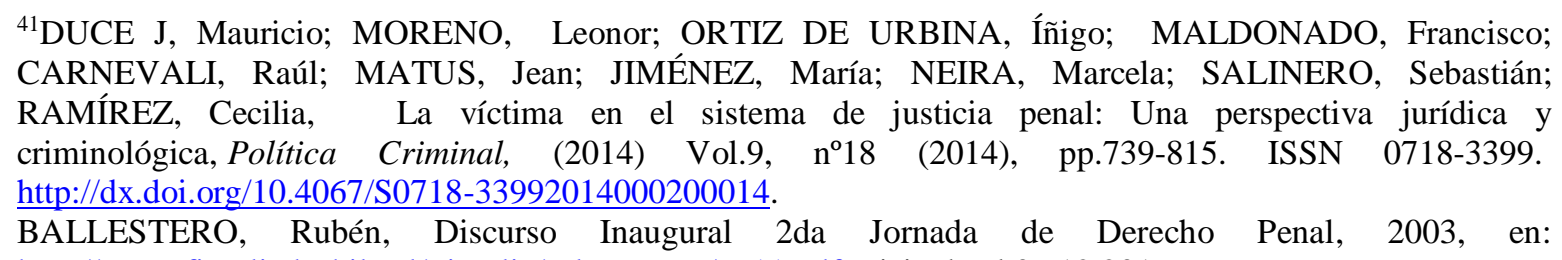
http://www.fiscaliadechile.cl/Fiscalia/sala_prensa/6_11.pdf [visitado el 07.12.2017]. 
REYES-QUILODRÁN; Claudia; A LABRENZ, Catherine; DONOSO-MORALES,

Gabriela. "Justicia Restaurativa en Sistemas de Justicia Penal Juvenil

Comparado: Suecia, Inglaterra, Italia y Chile".

artículo 6, Ley $\mathrm{N}^{\mathrm{o}} 20.084 .{ }^{42}$ Como consecuencia, estas son una manera de penalizar al adolescente por el daño provocado por el delito. De acuerdo a los profesionales entrevistados, en este contexto judicial, en muchas oportunidades la opinión del joven no es considerada, tampoco se visualizan las necesidades de la víctima, pues no se trata de un proceso voluntario, sino de una acción punitiva que se enfoca principalmente en el castigo y la sanción que emana de los Juzgados de Garantía.

\section{Análisis y Discusión de Resultados}

La fortaleza de la metodología de estudio comparado permite visualizar similitudes y diferencias en los casos que se comparan. ${ }^{43}$ Por lo tanto, los datos recogidos muestran un estado de desarrollo diferente en materia de JRJ en cada país. Es así como se observa que los tres países europeos cuentan con programas de mediación entre víctima y ofensor (VOM). Sin embargo, Inglaterra ha desarrollado otras formas de implementación de JRJ. Estos mismos resultados muestran que las prácticas restaurativas en Chile son escasas por lo tanto los resultados evidenciaron esa inequidad entre cada país. A su vez, los resultados muestran que la experiencia de la JRJ en los cuatro países es diferente. Sin embargo, a pesar de las diferencias es posible observar similitudes y estrategias comunes para enfrentar las barreras en la implementación de los programas de JRJ en cada uno de los casos. A continuación se discuten los resultados a partir de los elementos que emergen en la investigación.

En el caso de Italia, se observa que la participación de la comunidad y las familias en el proceso restaurativo es importante para el éxito del programa. Los profesionales señalan que el proceso restaurativo produce efectos en la cultura familiar. Un claro ejemplo de ello es el caso de que en la cultura italiana la venganza (vendetta) es permitida como forma de resolución de conflictos, provocando una escalada de la violencia. Con las prácticas de mediación en Sicilia y Torino, el equipo profesional percibe que la violencia disminuye, y que las personas comienzan a incorporar las prácticas restaurativas como una manera legítima de resolver los conflictos.

La barrera principal que enfrentaron los italianos era el apoyo de las autoridades para la implementación y financiamiento de los centros de mediación, lo que se superó a través de alianzas con universidades para ofrecer capacitaciones y recursos, y con la incorporación del sector privado.

El contacto de los jóvenes con el sistema penal es considerado por los entrevistados de Italia y Suecia como un factor de riesgo que les hace más susceptible a la violencia y al aumento en el compromiso delictual, incrementando las probabilidades de reincidencia cuando los jóvenes provienen de familias más vulnerables y con necesidades complejas. Bajo este escenario, las prácticas restaurativas constituyen una alternativa para prevenir que

\footnotetext{
${ }^{42}$ LEY N ${ }^{\circ} 20.084$, “Establece”, cit. nota n³4.

${ }^{43}$ GOODRICK, Delwyn. Comparative Case Studies, Methodological Briefs: Impact Evaluation 9, UNICEF Office of Research, Florence, en: http://devinfolive.info/impact_evaluation/ie/img/downloads/Comparative_Case_Studies_ENG.pdf [visitado el 07.12.2017].
} 
Polít. crim. Vol. 13, No 25 (Julio 2018) Doc. 2, pp. $626-649$.

[http://www.politicacriminal.cl/Vol_13/n_25/Vol13N25D2.pdf]

el adolescente y su familia sean expuestos ante el sistema penal, y permiten que las familias aborden las conductas desadaptativas de su hijo desde una manifestación temprana. Aunque en Chile aún no existe una comprensión completa de la JRJ y su impacto en la comunidad, hay un grupo creciente de personas interesadas en implementar estas prácticas y en aprender de la experiencia internacional. De hecho el Ministerio de Justicia y Derechos Humanos ha implantado un programa piloto en esta materia, el cual se encuentran en etapa de desarrollo.

Otro aspecto de la cultura italiana es que los italianos cuentan con Cortes de Menores específicamente para adolescentes en donde la sanción se aplica basado en un criterio de un profesional del área psicosocial (messa alla prova). En Chile a partir de la Ley $\mathrm{N}^{\mathrm{o}} 20.084,{ }^{44}$ el sistema penal juvenil en Chile no toma como primera consideración los problemas biopsicosociales de los jóvenes en la aplicación de la sentencia, ya que no consideraría los factores de riesgo que motivan al joven a delinquir ${ }^{45}$ demostrando no tener una amplia comprensión de los factores incidentes en la conducta delictiva juvenil que se separan del perfil adulto. ${ }^{46}$ Este aspecto se evidencia en el artículo 21 de la Ley que establece que la pena debe estar basada en el Párrafo 4 del Título III del Libro I del Código Penal. Esta característica también puede llegar a redundar en que la sanción aplicada no sea la más pertinente ante las necesidades psicosociales del adolescente y por ende dañe su desarrollo integral. En efecto, una de las grandes inquietudes manifestadas por los entrevistados en Chile era que en forma reiterada se aplicaban sanciones simultaneas. Más aún estas sanciones son de distintos nivel de punibilidad y se aplican indistintamente del nivel de compromiso delictual de cada joven, dificultando realizar intervenciones psicosociales acorde a las características de cada uno de ellos. Asimismo, los entrevistados argumentan que en los programas ambulatorios, a los adolescentes con un gran compromiso delictual y refractarios a la intervención, no se les realiza un seguimiento pos egreso que permita conocer su proceso de reinserción social.

Estos hallazgos develan que la respuesta del sistema penal en Chile tiende a ser punitiva, y la sanción podría no responder a las necesidades del joven. Contrario a esta visión, los entrevistados italianos señalan que el sistema penal juvenil Italiano pone como prioridad a las necesidades del joven, como una base para el plan psicosocial de intervención, y sus familias participan en este proceso. Esto les permite a los jóvenes visualizar el daño causado a la víctima y a la comunidad, y así pueden generar acciones concretas para reparar dicho daño.

En Italia se considera las necesidades biopsicosociales de los jóvenes infractores dentro del marco legal, por lo que la JR puede ser una herramienta útil para aumentar los niveles de empatía en el adolescente infractor e identificar las causas que lo motivan a delinquir. A

\footnotetext{
${ }^{44}$ LEY N 20.084 , "Establece", cit. nota n 34.

${ }^{45}$ FARRINGTON, David, "Explaining and preventing crime: The globalization of knowledge", Criminology, $\mathrm{N}^{\circ} 38$ (2000), pp. 1-24.

${ }^{46}$ KELLY, Richards. What makes juvenile offenders different from adult offenders? Trends \& issues in crime and criminal justice, $\mathrm{N}^{\circ} \quad 409, \quad$ (2011)), en: http://www.aic.gov.au/media_library/publications/tandi_pdf/tandi409.pdf [visitado el 07.12.2017].
} 
REYES-QUILODRÁN; Claudia; A LABRENZ, Catherine; DONOSO-MORALES,

Gabriela. "Justicia Restaurativa en Sistemas de Justicia Penal Juvenil

Comparado: Suecia, Inglaterra, Italia y Chile".

través de esta práctica, se pueden encontrar soluciones más integrales, que ayudan a prevenir la reincidencia y reducir el daño que implica la perpetración de un delito.

En Suecia, los profesionales indicaron que una de las barreras principales para la ejecución de las prácticas restaurativas era la descentralización de los programas, y proponen como solución el establecer una organización federal que pudiera implementar y regular VOM. Este aspecto es relevante dado que uno de los principios de la JR es la participación comunitaria, y para ello es fundamental que las intervenciones se realicen en el territorio en donde la comunidad se haga parte de lo que sucede con sus adolescentes. Por lo tanto, de acuerdos a los entrevistados en Suecia, se requiere de una instancia centralizada que realice estas dos funciones. Es decir, por un lado coordine y monitoree el desarrollo de las prácticas restaurativas en el territorio, y al mismo tiempo genere directrices comunes a nivel nacional, como en el caso de Italia. En los cuatro países estudiados, los entrevistados manifiesta la necesidad de que los distintos actores del sistema de justicia penal juvenil (jueces, defensores, fiscales, policías, servicios que implementan la sanción) se involucren en esta práctica entendiendo que se busca alinear esfuerzos en pro de la reinserción social de los adolescente, como también de la creación de vínculos de confianza con la comunidad. Para lo cual resultó fundamental en los tres países europeos, la necesidad de sensibilización y capacitación de estos actores en materia de justicia restaurativa, de tal forma de que lograron compartir una visión en común respecto a lo que se espera de un programa VOM. Como resultado de estas capacitaciones los distintos actores (dependiendo de la estructura de cada sistema judicial) derivaron casos a los programas y visualizaron los beneficios obtenidos por la víctima y por el adolescente infractor de ley.

Aunque el sistema penal juvenil en Inglaterra es bastante punitivo en comparación a Italia y Suecia, ellos han implementado numerosos programas preventivos ${ }^{47}$ para así también evitar la participación e involucramiento de los jóvenes en delitos. Los programas preventivos incluyen a la familia, a la comunidad y ponen especial énfasis a las etapas de desarrollo del adolescente. En el caso de Inglaterra, la JRJ tiene un alto impacto en la víctima y en el infractor, y este éxito lo atribuyen a la preparación de los profesionales en el modelo restaurativo, ya que cuentan con el conocimiento necesario para su implementación. En este aspecto, los programas de atención a los adolescentes infractores de ley pueden agregar prácticas restaurativas dentro de los objetivos de intervención, previo entrenamiento de los equipos profesionales.

A pesar del amplio rango de los marcos legales y de los sistemas penales juveniles en los distintos países estudiados, se observa que es absolutamente posible implementar prácticas en JR. La Comunidad Europea en conjunto con las Naciones Unidas visualizan los resultados de la JR en forma positiva, y esto se debe no sólo al nuevo paradigma judicial

\footnotetext{
${ }^{47}$ HOUSE OF COMMONS, Education Committee Children first: the child protection system in England, Fourth Report of Session 2012-13, Noviembre 2012, en: https://publications.parliament.uk/pa/cm201213/cmselect/cmeduc/137/137.pdf [visitado el 07.12.2017]. INSPECTION OF YOUTH OFFENDING \& CRIMINAL JUSTICE JOINT INSPECTION, A Joint Inspection of Youth Crime Prevention, September 2010, en: https://www.cqc.org.uk/sites/default/files/documents/joint_report_on_youth_crime_prevention.pdf [visitado el 07.12.2017].
} 
Polít. crim. Vol. 13, No 25 (Julio 2018) Doc. 2, pp. $626-649$.

[http://www.politicacriminal.cl/Vol_13/n_25/Vol13N25D2.pdf]

que éste implica, sino también a que es una alternativa que lidera cambios en la cultura y en las sociedades, pues propone al mundo occidental nuevas formas de resolver conflictos y abre espacio para a la paz.

Conocer la experiencia de países que llevan a cabo estas prácticas restaurativas, abre un espacio de aprendizajes en países como Chile que se encuentra en un etapa temprana de implementación. Chile, durante los años 70 al igual que varios países latinoamericanos, se vio afectado por el establecimiento de un régimen militar, y con ello la invaluable pérdida de vidas humanas. ${ }^{48}$ Desafortunadamente, la violencia política no sólo generó la división ideológica entre los ciudadanos, sino también las víctimas de violación de derechos humanos tendieron a perder la confianza en el sistema de justicia criminal. En este nuevo paradigma que entrega la JR permite que los ciudadanos sean los principales protagonistas y abre un espacio para recobrar la confianza en los sistemas judiciales, condición imprescindible para una sociedad democrática y republicana.

\section{Conclusiones}

Estos resultados nos permiten conocer desde los actores cómo se implementan las prácticas en escenarios socioculturales diversos. Asimismo, es posible visualizar cómo se implementan las prácticas de JRJ en Suecia, Inglaterra, Italia y Chile, y cómo las políticas públicas y el sistema de justicia penal juvenil de cada país facilitan este proceso, y qué barreras debieron enfrentar para la implementación de la JRJ. Este estudio comparado tiene ofrece un marco referencial que puede ayudar a orientar la puesta en marcha de procesos restaurativos en un país como Chile, que se encuentra en una etapa temprana de implementación.

La experiencia internacional, además, nos presentan una comprensión diferente de la conducta delictiva juvenil e invitan a visualizar la intervención como una forma de contribuir en el desarrollo integral de la población infantojuvenil y a generar cambios en la cultura, como lo muestra el caso de Italia.

Un gran desafío para Chile no sólo dista en la incorporación de estas prácticas en forma extensa en la población, sino en cómo se pueden abordar estas prácticas restaurativas desde una visión de oportunidad de aprendizaje en los adolescentes.

\footnotetext{
${ }^{48}$ NEVER AGAIN, Nunca Más: Never Again: A Report by Argentina's National Commission on Disappeared People, Great Britain: Butter and Tanner Ltd. Frame, Somerset and London, 1986.

RETTIG, Raúl; CASTILlO, Jaime; CEA, José; JIMÉNEZ, Mónica; MARTÍN, Ricardo; NOVOA, Laura; VIAL, Gonzalo; ZALAQUETT, José; CORREA, Jorge, Informe de la nacional comisión de verdad y reconciliación, Gobierno de Chile,1991, en: http://www.gob.cl/informe-rettig/[visitado el 07.12.2017]. VALECH, Sergio; SEPÚlVEDA, María; AMUNÁTEGUI, Miguel; FOUILLIOUX, Luciano; GÓMEZ, José; LIRA, Elizabeth; SIERRA, Lucas; VARELA, Álvaro, Informe de la comisión nacional de prisión política y tortura, Gobierno de Chile, 2004, en: http://www.ben.cl/bibliodigital/dhisto/lfs/Informe.pdf/ [visitado el 07.12.2017].
} 
REYES-QUILODRÁN; Claudia; A LABRENZ, Catherine; DONOSO-MORALES,

Gabriela. "Justicia Restaurativa en Sistemas de Justicia Penal Juvenil

Comparado: Suecia, Inglaterra, Italia y Chile".

\section{Bibliografía}

ACTA DEL CRIMEN Y DESORDEN - Crime and Disorder Act, Established the Youth Justice System of England and Wale's legal support, 1988, en: http://www.legislation.gov.uk/ukpga/1998/37 [visitado el 07.12.2017].

AGUIRREZABAL, Maite; LAGOS, Gladys; VARGAS, Tatiana "Responsabilidad penal juvenil: hacia una justicia individualizada", Revista de Derecho (Valdivia), vol. XXII, $\quad \mathrm{n}^{\mathrm{o}} \quad 2, \quad$ (2009), $\quad$ pp. 137-159, en: http://www.redalyc.org/pdf/1737/173714177008.pdf [visitado el 07.12.2017].

ANSARI, Sami, "Social Capital and Collective Efficacy: Resource and Operating Tools of Community Social Control", Journal of Theoretical and Philosophical Criminology Social Capital \& Collective Efficacy, Vol. 5 n² (2013), pp. 75- 94.

AXELSSON, Erik, Young Offenders and Juvenile Justice in Sweden. Riksdag Research Service Stockholm, Sweden SN/SG/5278, 2008.

BALLESTERO, Rubén. Discurso Inaugural 2da Jornada de Derecho Penal, (2003), en: http://www.fiscaliadechile.cl/Fiscalia/sala_prensa/6_11.pdf [visitado el 07.12.2017].

BERGSETH, Kathleen; COOPER, Maisha; BOUFFARD, Jeff, "Examining the effectiveness of a restorative justice program for various types of juvenile offenders", International Journal of Offender Therapy and Comparative Criminology, nº57 (2012), pp.1054-1075.

BONTA, James; WALLACE-CAPRETTA, Suzanne; ROONEY, Jennifer, Restorative Justice: An evaluation of the Restorative Resolutions Project, Ottawa: Solicitor General Canada, 1998, en: https://www.ncjrs.gov/App/Publications/abstract.aspx?ID=181381[visitado el 07.12.2017].

BRAITHWAITE, John, "Pride in criminological dissensus", Law \& Social Inquiry, Vol. $18, n^{\circ} 3$ (1993), pp. 501-512.

BRAITHWAITE, John, Restorative Justice and Responsive Regulation. New York, Oxford University Press. 2002.

BRAITHWAITE, John, Restorative Justice and Responsive Regulation: The Question of Evidence, Regnet Research Paper No. 2014/51, Australian National University, 2014, file:///C:/Users/Usuario/Downloads/SSRN-id2514127.pdf [visitado el 07.12.2017].

BRAITHWAITE, John, "Restorative justice: Assessing optimistic and pessimistic accounts", Crime and Justice, no 25 (1999), pp. 1-127. 
Polít. crim. Vol. 13, No 25 (Julio 2018) Doc. 2, pp. $626-649$.

[http://www.politicacriminal.cl/Vol_13/n_25/Vol13N25D2.pdf]

BUSTOS, Juan, Derecho Penal del Niño-Adolescente. Ediciones Jurídicas de Santiago, Santiago, 2007.

CONVENCIÓN SOBRE LOS DERECHOS DEL NIÑO, Naciones Unidas. 1989. http://www.unicef.cl/web/informes/derechos_nino/convencion.pdf [visitado el 07.12.2017].

CHRISTIE, Nils, “Conflict as property”, British Journal of Criminology, n 17(1977), pp. $1-15$.

CRESWELL, John, Qualitative inquiry and research design: Choosing among five approaches ( $2^{\text {nd }}$ edition), Thousand Oaks, CA: Sage Publications, 2007.

DABAS, Elina; NAJMANOVICH, Denise, Redes: El lenguaje de los vínculos hacia la construcción el fortalecimiento de la sociedad civil, Buenos Aires, Argentina: Paidós. 1999.

DECRETO No 448/1988, Approvazione delle disposizioni sul processo penale a carico di imputati minorenni, Decreto del Presidente della Repubblica, 1988, 448/88, en: http://www.altrodiritto.unifi.it/ricerche/minori/rugi/cap2.htm [visitado el 07.12.2017].

DECRETO LEGISLATIVO No 272/1989, Approvazione delle disposizioni sul processo penale a carico di imputati minorenni, DL 272/89, 1989, en: http://www.regione.abruzzo.it/procuraminori/docs/legislazione/Norme_attuative_ DLgs_28071989.pdf [visitado el 07.12.2017].

DECRETO LEGISLATIVO No 274/2000, "Disposizioni sulla competenza penale del giudice di pace, a norma dell'articolo 14 della legge 24 novembre 1999, n. 468", 2000, en: http://www.camera.it/parlam/leggi/deleghe/00274dl.htm [visitado el 07.12.2017].

DUCE J, Mauricio; MORENO, Leonor; ORTIZ DE URBINA, Íñigo; MALDONADO, Francisco; CARNEVALI, Raúl; MATUS, Jean; JIMÉNEZ, María; NEIRA, Marcela; SALINERO, Sebastián; RAMÍREZ, Cecilia, "La víctima en el sistema de justicia penal: Una perspectiva jurídica y criminológica”, Política Criminal, (2014) Vol.9, n.18, (2014), pp.739-815. ISSN 0718-3399,en: http://dx.doi.org/10.4067/S0718-33992014000200014.

EUROPEAN UNION COUNCIL, Framework Decision: The standing of victims in criminal proceedings, Article 10, 15 of March 2001, en: http://eurlex.europa.eu/legal-content/EN/TXT/?uri=CELEX\%3A32001F0220 [visitado el 07.12.2017].

EUROPEAN PARLIAMENT, European Network of National Contact Points for Restorative Justice, 2003, EUROPEAN PARLIAMENT, European Network of 
REYES-QUILODRÁN; Claudia; A LABRENZ, Catherine; DONOSO-MORALES,

Gabriela. "Justicia Restaurativa en Sistemas de Justicia Penal Juvenil

Comparado: Suecia, Inglaterra, Italia y Chile".

National Contact Points for Restorative Justice. 2003, en: http://www.europarl.europa.eu/sides/getDoc.do?pubRef=-

//EP//NONSGML+TA+P5-TA-2003-0147+0+DOC+PDF+V0//EN [visitado el 07.12.2017].

FARRINGTON, David, "Explaining and preventing crime: The globalization of knowledge", Criminology, $\quad \mathrm{n}^{\mathrm{o}} 38 \quad$ (2000), pp. 1-24. $\quad$ DOI: $10.1111 / \mathrm{j} .1745-$ 9125.2000.tb00881.x

GOODRICK, Delwyn. Comparative Case Studies, Methodological Briefs: Impact Evaluation 9, UNICEF Office of Research, Florence, 2014, en: http://devinfolive.info/impact_evaluation/ie/img/downloads/Comparative_Case_S tudies_ENG.pdf [visitado el 07.12.2017].

HARRENDORF, Stefan; HEISKANEN, Markku; MALVY, Steven,International statistics on crime and justice, European Institute for Crime Prevention and Control Affiliated with United Nations, 2010, en: https://www.unodc.org/documents/dataand-analysis/Crime-statistics/International_Statistics_on_Crime_and_Justice.pdf [visitado el 07.12.2017].

HOUSE OF COMMONS. Education Committee Children first: the child protection system in England Fourth Report of Session 2012-13, Noviembre 2012, en: https://publications.parliament.uk/pa/cm201213/cmselect/cmeduc/137/137.pdf [visitado el 07.12.2017].

HAYES, Hennessey; DALY, Kathleen, "Conferencing and re-offending in Queensland", Australian and New Zealand Journal of Criminology, $\mathrm{n}^{\circ} 37$ (2004), pp.167-191. http://journals.sagepub.com/doi/abs/10.1375/acri.38.1.77

JACOBSSON, Maritha; WAHLIN, Lottie; ANDERSSON, Tommy, "Victim offender mediation in Sweden: Is the victim better off?" International Review of Victimology, Vol. 18, n³ (2012), pp. 229-249. http://journals.sagepub.com/doi/pdf/10.1177/0269758012446985

KELLY, Richards, What makes juvenile offenders different from adult offenders? Trends \& issues in crime and criminal justice, $\mathrm{N}^{\mathrm{o}}$ 409, 2011, en: http://www.aic.gov.au/media_library/publications/tandi_pdf/tandi409.pdf [visitado el 07.12.2017].

INSPECTION OF YOUTH OFFENDING \& CRIMINAL JUSTICE JOINT INSPECTION. A Joint Inspection of Youth Crime Prevention, September 2010, en: https://www.cqc.org.uk/sites/default/files/documents/joint_report_on_youth_crim e_prevention.pdf [visitado el 07.12.2017].

LATIMER, Jeff; KLEINKNECHT, Steven, The Effects of Restorative Justice 
Polít. crim. Vol. 13, No 25 (Julio 2018) Doc. 2, pp. $626-649$.

[http://www.politicacriminal.cl/Vol_13/n_25/Vol13N25D2.pdf]

Programming: A review of the empirical, Ottawa: Department of Justice, Research and Statistics Division, 2000, en: http://www.justiciarestaurativa.org/www.restorativejustice.org/articlesdb/articles/ $\underline{1829}$ [visitado el 07.12.2017].

LEY N ${ }^{\circ}$ 2002:445, Mediation Act 445, Lag om medling med anledning av brott [Mediation Act], Swedish Code of Statutes, Stockholm, 2002, en: https://www.riksdagen.se/sv/dokument-lagar/dokument/svenskforfattningssamling/lag-2002445-om-medling-med-anledning-av-brott_sfs-2002$\underline{445}$ [visitado el 07.12.2017].

LEY No 20.084, Establece un Sistema de Responsabilidad de los Adolescentes por Infracciones a la Ley Penal, Ministerio de Justicia, Chile, 2007, en https://www.leychile.cl/Navegar?idNorma=244803[visitado el 07.12.2017].

LEY No 20.032. Establece Sistema de Atención a la Niñez y Adolescencia A través de la Red de Colaboradores del SENAME, y su Régimen de Subvención, Ministerio de Justicia, Chile, 2015, en: http://www.sename.cl/wsename/otros/proteccion/ley20032.pdf [visitado el 07.12.2017].

LEY No 285 Disposizioni per la promozione di diritti e di opportunità per l'infanzia e l'adolescenza, Gazzetta Ufficiale, 1997, en: http://www.camera.it/parlam/leggi/972851.htm [visitado el 07.12.2017].

MCCOLD, Paul; WACHTEL, Benjamin, Restorative Policing Experiment the Bethlehem Pennsylvania Police Family Group Conferencing Project, Community Service Foundation Pipersville, PA, 1998, http://www.iirp.edu/pdf/BPD.pdf

MELO, Ronaldo, Guardar silencio: El desafío de la especialización en el sistema de justicia penal adolescente, Revista 93: La revista de la Defensoría Nacional Pública, Vol. 9 (2013), pp. 55-57, Gobierno de Chile, en: http://www.dpp.cl/resources/descargas/revista93/revista93n9.pdf [visitado el 07.12.2017].

NACIONES UNIDAS, Manual sobre Programas de Justicia Restaurativa, United Nations Office on Drugs and Crime, New York, 2006, https://www.unodc.org/documents/justice-and-prisonreform/Manual_sobre_programas_de_justicia_restaurativa.pdf [visitado el 07.12.2017].

NELKEN, David, “Italian juvenile justice: Tolerance, leniency or indulgence?”, Youth Justice, Vol. 6, n² (2006), pp. 107-128. DOI: 10.1177/1473225406065561 
REYES-QUILODRÁN; Claudia; A LABRENZ, Catherine; DONOSO-MORALES,

Gabriela. "Justicia Restaurativa en Sistemas de Justicia Penal Juvenil

Comparado: Suecia, Inglaterra, Italia y Chile".

NEVER AGAIN, Nunca Más: Never Again: A Report by Argentina's National Commission on Disappeared People, Great Britain: Butter and Tanner Ltd. Frame, Somerset and London, 1986.

OYARZÚN Astrid, DÁVILA Oscar, GHIARDO, Felipe, HATIBOVIC, Fuad ¿Enfoque de derechos o enfoque de necesidades? Centro de Estudios Sociales. SENAME, 2008, en: http://es.scribd.com/doc/92434342/Enfoque-de-Derecho-o-Enfoque-deNecesidades. [visitado el 07.12.2017].

PAILLE, Pierre, La méthodologie qualitative: Postures de recherche et travail de terrain, Paris, Francia: Armand Colin, 2006.

PADILLA, Marcelo, "Examen y Contraexamen: Iván Fuenzalida y Sebastián Valenzuela", Revista 93: La revista de la Defensoría Nacional Pública, Vol. 9 (2013). pp. 1420. Gobierno de Chile,en: http://www.dpp.cl/resources/descargas/revista93/revista93n9.pdf [visitado el 07.12.2017].

PUTMAN, Robert, Bowling alone: The collapse and revival of American community. New York, NY: SAGE, 2000.

RODRIGUEZ, Nancy, "Restorative Justice, Communities, and Delinquency: Whom Do We Reintegrate?", Criminology and Public Policy, Vol. 4, nº 1 (2005), pp. 103130 .

http://onlinelibrary.wiley.com/doi/10.1111/j.1745-

9133.2005.00010.x/abstract

RETTIG, Raúl; CASTILLO, Jaime; CEA, José; JIMÉNEZ, Mónica; MARTÍN, Ricardo; NOVOA, Laura; VIAL, Gonzalo; ZALAQUETT, José; CORREA, Jorge. Informe de la nacional comisión de verdad y reconciliación, Gobierno de Chile, 1991, en: http://www.gob.cl/informe-rettig/[ visitado el 07.12.2017].

VALECH, Sergio; SEPÚlVEDA, María; AMUNÁTEGUI, Miguel; FOUILLIOUX, Luciano; GÓMEZ, José; LIRA, Elizabeth; SIERRA, Lucas; VARELA, Álvaro, Informe de la comisión nacional de prisión política y tortura, Gobierno de Chile, 2004, en:

http://www.bcn.cl/bibliodigital/dhisto/lfs/Informe.pdf/ [visitado el 07.12.2017].

SWEDISH PENAL CODE, Chapter 29, Section 7. Stockholm, Sweden, 1962, en: http://www.parliament.am/library/Qreakan/shwedia.pdf [visitado el 07.12.2017].

WAHLIN, Lottie, Victim offender mediation in the $21^{\text {st }}$ Century, National Council for Crime Prevention, Stockholm, Sweden, 2005, en: https://www.bra.se/download/18.cba82f7130f475a2f1800026027/1371914734461 /2005_victim-offender_mediation_in_sweden.pdf [visitado el 07.12.2017].

WEITEKAMP, Elmar, “The History of Restorative Justice”, en BAZEMORE, Gordon and 
Polít. crim. Vol. 13, No 25 (Julio 2018) Doc. 2, pp. $626-649$.

[http://www.politicacriminal.cl/Vol_13/n_25/Vol13N25D2.pdf]

WALGRAVE, Lode, Restorative Juvenile Justice: Repairing the Harm of Youth Crime. New York: Criminal Justice Press, 1999, pp. 75-102.

WOOD, William, Why Restorative Justice Will Not Reduce Incarceration, The British Journal of Criminology $\mathrm{n}^{\mathrm{o}} \quad 55 \quad$ (2015), pp. 883-900. https://academic.oup.com/bjc/article/55/5/883/478399/Why-Restorative-JusticeWill-Not-Reduce

WRIGHT, Martin, "Making good: Prisons, punishment and beyond", The Journal of Criminal Law and Criminology, no 74 (1983), pp. 1635-1638.

YOUTH JUSTICE BOARD, Developing restorative justice: An action plan, London. 2006, en: http://restorativejustice.org/rj-library/developing-restorative-justice-anaction-plan/7508/\#sthash.Fv0IBqEq.dpbs [visitado el 07.12.2017]. 